\title{
Laboreal
}

Volume $4 \mathrm{~N}^{\circ} 1$ | 2008

Ergologia, trabalho, desenvolvimentos

\section{Análise da actividade de transmissão escrita durante as passagens de turno no hospital : avaliação ergonómica do uso de um novo formato de escrita}

Análisis de la actividad de transmisión escrita durante los cambios de turno en el hospital : evaluación ergonómica del uso de un nuevo formato de escrita Analyse de l'activité de transmission écrite au cours des relèves de poste à l'hôpital : Évaluation ergonomique de l'usage d'un nouveau format d'écriture Analysis of the written handover process during shift changes within the hospital: an ergonomic evaluation of the use of a new writing format

Jean-Michel Boucheix e Michèle Coiron

Tradutor: Gil Mata

\section{OpenEdition}

\section{Journals}

Edição electrónica

URL: http://journals.openedition.org/laboreal/12005

DOI: $10.4000 /$ laboreal. 12005

ISSN: 1646-5237

Editora

Universidade do Porto

Refêrencia eletrónica

Jean-Michel Boucheix e Michèle Coiron, « Análise da actividade de transmissão escrita durante as passagens de turno no hospital : avaliação ergonómica do uso de um novo formato de escrita », Laboreal [Online], Volume $4 \mathrm{~N}^{0} 1$ | 2008, posto online no dia 01 julho 2008, consultado o 17 outubro 2019. URL : http://journals.openedition.org/laboreal/12005; DOI : 10.4000/laboreal.12005

Este documento foi criado de forma automática no dia 17 outubro 2019.

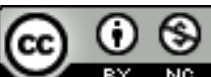

Laboreal está licenciado com uma Licença Creative Commons - Atribuição-NãoComercial 4.0 Internacional. 


\section{Análise da actividade de transmissão escrita durante as passagens de turno no hospital : avaliação ergonómica do uso de um novo formato de escrita}

Análisis de la actividad de transmisión escrita durante los cambios de turno en el hospital : evaluación ergonómica del uso de un nuevo formato de escrita Analyse de l'activité de transmission écrite au cours des relèves de poste à l'hôpital : Évaluation ergonomique de l'usage d'un nouveau format d'écriture Analysis of the written handover process during shift changes within the hospital : an ergonomic evaluation of the use of a new writing format Jean-Michel Boucheix e Michèle Coiron Tradução : Gil Mata

\section{REFERÊNCIA}

Artigo original : Boucheix, J.-M \& Coiron, M. (2008). Analyse de l'activité de transmission écrite au cours des relèves de poste à l'hôpital : Évaluation ergonomique de l'usage d'un nouveau format d'écriture. @ctivités, 5 (1) pp. 79-102, http:// www.activites.org/v5n1/v5n1.pdf

\section{Introdução}

1 Através de uma análise da actividade das passagens de turno entre enfermeiras, o objectivo deste trabalho é avaliar a ergonomia de um novo formato de escrita das 
transmissões escritas, concebido e prescrito pela instituição hospitalar. Num contexto de optimização da "qualidade" do acompanhamento dos pacientes, numerosas estruturas hospitalares desejavam satisfazer os critérios de acreditação dos estabelecimentos de cuidados de saúde. Esta démarche prescrevia a utilização de indicadores de rastreamento do trabalho. Estes são associados a uma exigência de "eficiência acrescida", num contexto de diminuição dos custos de hospitalização e aumento das entradas e saídas de curta duração associadas à utilização crescente de tecnologia de exploração médica. Em suma, a carga informativa cresce, enquanto os dados contextuais sobre os pacientes diminuem. Neste contexto, o CHU (de uma cidade de 250000 habitantes) concebeu e desenvolveu, em parceria com o pessoal do quadro de enfermagem, uma nova estrutura textual, formal, de transmissão escrita do trabalho da enfermeira nas passagens de turno.

2 As transmissões chamadas "orientadas" têm como objectivo realçar o que é escrito, sobre cada paciente, num alvo, isto é, numa informação pertinente proveniente da última passagem de turno, e então desenvolver informação sobre este alvo de acordo com uma estrutura formal composta por três critérios : os Dados, as Acções levadas a cabo e os Resultados obtidos (D.A.R., cf. tabela 1 e abaixo). A finalidade desta nova prescrição é assegurar um melhor acompanhamento, em tempo real e preciso, do estado do paciente, seleccionando aspectos significativos da evolução do paciente (sistema dinâmico, Cellier, De Keyser \& Valot, 1996 ; Hoc, 1996). Deste modo, poderia efectuar-se um controlo on-line das transformações quotidianas do estado do paciente, visíveis, rastreáveis, reduzindo, portanto, o mais possível, o risco de incidentes pósoperatórios.

3 A concepção e uso desta nova "ferramenta de escrita", usada no CHU envolvido neste estudo, foram realizadas antes da nossa intervenção, sem qualquer análise prévia da actividade regular de escrita espontaneamente realizada pelo pessoal de enfermagem. Contudo, as enfermeiras têm uma longa prática da transmissão e a questão que se pode colocar é se este novo formato é adequado às necessidades reais das enfermeiras. Para a instituição, a razão para implementar este novo formato parecia ser dupla : dispor de documentos que permitissem um rastreamento do trabalho de enfermagem e conceber uma ajuda para a redaç̧ão de transmissões escritas precisas. Será que o formato de transmissão proposto se adapta a estes objectivos? Deparados com as dificuldades relatadas pelas profissionais, subsequentes à introdução desta nova prescrição, o pedido inicial que a instituição hospitalar nos fez foi de construir um curso de formação profissional com o objectivo de desenvolver as competências das enfermeiras para a redacção deste formato específico, de transmissões escritas ditas "orientadas".

Antes de considerar qualquer tipo de actividade formativa, pareceu-nos necessário, no plano ergonómico, verificar a adequação desta ferramenta de redacção à actividade de transmissão das enfermeiras durante a passagem de turno (de Montmollin, 1986; Rogalski \& Samurçay, 1994 ; Leplat, 1997 ; Pastré, 1997 ; Boucheix, 2003). O objectivo do trabalho apresentado neste artigo é avaliar a adaptação ergonómica deste novo formato de redacção das transmissões escritas, prescrito pelo hospital, de acordo com as necessidades das profissionais envolvidas no momento da passagem de turno. Para o fazer, conduzimos uma análise da actividade de transmissão oral e escrita durante a passagem de turno de nove enfermeiras, responsáveis por 70 pacientes. Esta análise foi precedida de um estudo do período de actividade com estes pacientes antes da passagem. Prestámos atenção particular à dimensão da filtragem de informação. $\mathrm{Na}$ 
conclusão do nosso estudo, iremos fazer recomendações para a optimização destas notas escritas.

\subsection{O que é a transmissão orientada, D.A.R ? Análise da prescrição}

O nosso objectivo é avaliar o uso de notas escritas orientadas, mas o que é uma transmissão escrita dita "orientada" ? Iremos então apresentar, primeiramente, os benefícios que eram esperados, a priori, pelo hospital, da implementação de transmissões orientadas e uma análise dos constrangimentos inerentes a esta nova prescrição.

Primeiro, a troca orientada (ver o exemplo apresentado na tabela 1) envolveria uma triagem da informação respeitante à evolução do paciente. Esta triagem exige escolher um alvo que corresponda a uma informação nova e pertinente, respeitante ao paciente e desenvolver as informações clínicas que dizem respeito a este alvo. Este é escolhido pela enfermeira. À volta de um tema central chamado o alvo, as informações que o descrevem devem ser classificadas de acordo com três critérios : os Dados, as Acções, e os Resultados : D.A.R. Um exemplo da transformação de uma transmissão "habitual" (proveniente da nossa amostra) numa transmissão orientada, é apresentada na tabela 1.

Tabela 1 : Exemplo de transmissão orientada em formato D.A.R. (Dados, Acções, Resultados)

\begin{tabular}{|c|c|c|c|c|}
\hline \multicolumn{5}{|c|}{ Transmissão anterior à transmissão orientada } \\
\hline Data & Nome & & & \\
\hline $6 / 04 / 98$ & $\mathrm{x}$ & \multicolumn{3}{|c|}{$\begin{array}{l}\text { Estava com dores no início da noite, acalmado com Prodaf, } \\
\text { quase não dormiu }\end{array}$} \\
\hline \multicolumn{5}{|c|}{ Transmissão orientada } \\
\hline Data & Nome & Alvo & DAR & \\
\hline \multirow[t]{2}{*}{$6 / 04 / 98$} & $\mathrm{x}$ & Dor & D & $\begin{array}{l}\text { Dor abdominal intensa, posição antálgica } \\
\text { com pernas encolhidas, gemidos }\end{array}$ \\
\hline & & & A & Injecção com Prodalfon e Spasfon \\
\hline $21 \mathrm{~h}$ & & & $\mathbf{R}$ & Paciente acalmado, não se queixa mais \\
\hline \multicolumn{5}{|c|}{ Tabela 1: Exemplo de transmissão orientada em formato D.A.R. (Dados, Aç̣ōes, Resultados) } \\
\hline
\end{tabular}

Segundo a prescrição, o critério para escolher o alvo corresponde à "ocorrência de um evento fisiológico ou psicológico, de um estado ou sensação que não estava presente, $\mathrm{e}$ que modifica a situação do paciente". Esta escolha parece falsamente simples. Ela envolve seleccionar a informação memorizada proveniente da prestação de cuidados. Dois tipos de critério determinam esta selecção. $O$ primeiro diz respeito à pertinência, isto é, a pertinência e novidade da informação fornecida quando comparada com a patologia e o prognóstico previsto de evolução da saúde do paciente. Uma vez a escolha sendo feita nesta dimensão, a enfermeira deve mudar o seu modo habitual de registar as informações, isto é, seguindo uma ordem que é conforme à recuperação espontânea 
de informações em memória (cronológica, tal como no exemplo da Tabela 1 ; "estava com dores no início da noite, acalmado com Prodaf...”), para um modo de organização das informações escritas segundo uma classificação de acordo com uma nomenclatura ou nova categorização. $O$ desenvolvimento das informações que dizem respeito ao alvo escolhido deve ser realizado de acordo com a estrutura formal D.A.R. Do um ponto de vista operativo, não é claro que este novo formato seja realmente mais funcional do que o usado espontaneamente pelas enfermeiras. Acrescenta-se igualmente uma norma de aceitação "institucional" do que podemos escrever, comparado com o que podemos dizer durante a transmissão oral.

8 A transmissão orientada também teria o objectivo de melhorar a precisão das informações clínicas. No exemplo acima referido, a informação "sofreu toda a noite" seria expandida, de modo mais preciso, em "dor abdominal, posição antálgica com pernas encolhidas, gemidos”. Estas precisões poderiam fornecer indícios susceptíveis de optimizar o diagnóstico e antecipar eventos futuros. Estes diagnósticos, ditos de "enfermagem", correspondem a um julgamento clínico (diagnóstico e prognóstico) sobre a evolução do paciente, servindo de base (enquanto complemento à prescrição médica) para a escolha das prestações de cuidados da enfermeira. Esta analisa as reacções do paciente à prescrição do médico e antecipa os comportamentos criadores de risco, e regula o estado do paciente (conforto, bem-estar). Esta actividade, na qual se apoia a elaboração da transmissão escrita, é fundada em observações de "sinais clínicos", na produção de raciocínios (relacionando os sinais ao conhecimento anterior, seguindo de hipóteses). As decisões de acção podem assim ser previstas. Um exemplo de uma possível evolução de um diagnóstico deste tipo, a partir de manifestações clínicas, aparece no exemplo seguinte :

Diagnóstico actual, baseado em sinais: "Ansiedade associada à hospitalização, manifestando-se através de voz trémula"

Diagnóstico potencial, baseado em riscos : "Risco de infecção, associado a uma alteração do sistema imunitário"

11 Notemos, contudo, que no exemplo da Tabela 1, a formulação espontânea "Estava com dores no início da noite, acalmado com Prodaf, quase não dormiu" também contém informação mais centrada no vivido do paciente e na sua relação com este, enquanto que a transmissão orientada está mais próxima de um diagnóstico técnico "Dor abdominal intensa, posição antálgica com pernas encolhidas, gemidos. Injecção de Prodalfan e Spasfon. Paciente acalmado, não se queixa mais". Ora, a relação e o contacto com o paciente constituem aspectos fundamentais na prestação de cuidados.

Na transmissão orientada, seria também importante evitar as repetições. A orientação das informações permitiria reduzir a redundância significativa das transmissões de uma passagem de turno para outro. Contudo, deve notar-se que, por vezes, esta redundância pode ter uma funcionalidade. Uma apresentação padronizada facilitaria a recuperação da informação. A distribuição das informaç̃es desenvolvidas de acordo com a estrutura formal D.A.R. deveria optimizar a classificação das informações e facilitar a sua recuperação, sob a condição de que as enfermeiras se apropriassem da ferramenta.

13 Finalmente, devido ao objectivo de rastreamento, desejado pela instituição, a D.A.R. poderia induzir na enfermeira uma actividade de avaliação da "aceitabilidade" das informações desenvolvidas. De facto, um traço escrito tem um carácter permanente, acessível a várias categorias de destinatários. Este registo escrito também induz normas 
de aceitabilidade respeitantes ao tipo de informação escolhida, que podem ser diferentes dos da informação partilhada nas transmissões orais. Em suma, a redacção de transmissões orientadas iria envolver os constrangimentos seguintes: filtrar e seleccionar as informações, melhorar o conteúdo das descrições clínicas, integrar os diagnósticos das enfermeiras, evitar repetições de uma passagem de turno para outra e recuperar mais facilmente as informações do que no caso das notas não-estruturadas. Neste sentido, elas constituiriam séries de descrições sobre a evolução do estado de um organismo, comparável a um "sistema dinâmico" (Hoc, 1996). Mas será que esta formalização está adaptada à actividade da enfermeira?

\subsection{Dificuldades encontradas na implementação da transmissão orientada, D.A.R.}

O objectivo prescrito pela instituição durante a introdução das transmissões escritas era o de "capitalizar informações escritas fiáveis e práticas para assegurar a continuidade da prestação de cuidados" (texto prescritivo do processo de acreditação). O propósito desta nova prescrição era o da operacionalização do acompanhamento, pela enfermeira, do sistema dinâmico representado pelo paciente na relação com o médico. Mas, a enfermeira, especialmente quando experimentada, utiliza, há já muito tempo, competências operacionais de monitorização e transmissão através de suportes de informações escritas (notas dos tratamentos, folhas de acompanhamento, transmissões escritas habituais) assim como os métodos orais (transmissão oral) (cf. Errard, Kostulski \& Trognon, 1996). As enfermeiras já escolhem a informação nas suas práticas escritas habituais, tal como é mostrado no exemplo da Tabela 1. É durante estas actividades que as competências específicas do "diagnóstico de enfermagem" são desenvolvidas.

Os estudos que se debruçam sobre o trabalho hospitalar e particularmente sobre a transmissão oral mostraram que os profissionais desenvolvem com eficácia uma verdadeira inteligência e competência colectiva (Cosnier, Grosjean \& Lacoste, 1993; Grosjean \& Lacoste, 1999). Por outro lado, a passagem de turno não se reduz unicamente a uma transmissão de informação unilateral, ela representa uma interacção construtiva entre os interlocutores, durante a qual os problemas são analisados e resolvidos (Grusenmeyer, 1995, 1996; Grusenmeyer \& Trognon, 1996) tal como nas interacções das situações de serviço (Cerf, Valléry \& Boucheix, 2004 ; Falzon, 2004 ; Boucheix, 2005 ; Cerf \& Falzon, 2005 ; Valléry, Leduc, Boucheix \& Cerf, 2005). Grosjean e Lacoste (1999) mostraram que o escrito e o oral representam duas modalidades complementares de acompanhamento do paciente, servindo funcionalidades diferentes.

Do seu lado, os estudos de psicologia cognitiva sobre a produção da linguagem, têm também mostrado que a produção (ou interacção) oral e a produção escrita constituem duas modalidades de trabalho. Os constrangimentos funcionais de uma e outra modalidade são distintos (Bourdin, 1994; Heurley, 1994; Fayol, 1997; Alamargot \& Dansac, 2003). Num caso, o destinatário está presente e é simultaneamente activo num contexto de uma comunicação multimodal, acompanhada por numerosos feedbacks que ajudam a construir um referencial comum (Giboin, 2004), no outro caso, o destinatário está ausente. A transmissão orientada requer ao escritor que faça a gestão destes dois tipos de constrangimento. Do ponto de vista da redacção, trata-se de passar de uma 
escrita espontânea habitual de conhecimentos, vinda directamente da acção, que corresponde a uma estratégia de recuperação de conhecimentos da memória ao longo do processo de escrita (Fayol, 1997), para uma apresentação das informações, organizada em torno de temáticas escolhidas (entre outras possíveis) e segundo uma organização textual prescrita. Este segundo método implica o uso de uma estratégia de "transformação" de conhecimentos (Levelt, 1989 ; Levelt \& Maassen, 1991 ; Hayes \& Nash, 1996 ; Fayol, 1997), em função de um objectivo e um destinatário. Bourdin (1994) mostrou que este tipo de actividade de transformação era particularmente difícil. Para além disso, acrescentam-se constrangimentos de ordem sócio-institucional na redacção dos registos escritos de trabalho (Boutet, 1995) : tipo de destinatário, uso e estatuto do registo escrito, e uma avaliação subjacente da actividade dos profissionais através dos registos escritos. Em todos estes casos, trata-se de uma linguagem operativa (Falzon, 1989), mas esta é escrita e ainda muito é desconhecido sobre a linguagem operativa escrita.

Esta nova prescrição para escrita destina-se a todas as enfermeiras do CHU. Durante a sua concepção, que precedeu o pedido que nos foi formulado, não tinha sido feita nenhuma análise prévia da actividade dos profissionais ou da aceitabilidade desta nova ferramenta. Apenas tinha sido fornecida a informação. Antes da generalização planeada para o todo o $\mathrm{CHU}$, vários Serviços que estudámos já tinham adoptado a prática das transmissões orientadas do tipo DAR. Durante as nossas entrevistas exploratórias, o pessoal de enfermagem implicado referiu dificuldades no uso espontâneo dos procedimentos de escrita de transmissão orientada, enquanto exprimiam, simultaneamente, o desejo de melhorar essas transmissões. Começámos por conduzir uma primeira fase de observação exploratória directa com as enfermeiras, enquanto usavam a démarche da transmissão orientada (entrevista directa sobre o que era escrito e observações em situação) de modo a confirmar a realidade do problema. Estávamos, deste modo, a procurar melhor entender a definição e as representações que as enfermeiras concebiam da noção de alvo. Conseguimos distinguir as dificuldades declaradas seguintes :

- Ainda que o objectivo de uma transmissão escrita não seja substituir a transmissão oral, mas sim completá-la, existiria uma perda de informação demasiado importante entre a transmissão oral e a transmissão escrita, o que coloca o problema da selecção.

A escolha do alvo (categorização) e a formulação (em formato DAR) colocavam muitas vezes problemas. Esta dificuldade tinha por efeito o refúgio nos alvos "genéricos", resultantes não da identificação de sinais clínicos, mas do uso de nomenclaturas genéricas, clássicas na profissão, mas pouco informativas no que diz respeito à evolução do estado do paciente. Por exemplo, "alimentação", "respiração".

- A procura de informações precisas, que não estão sistematicamente acessíveis na altura da redacção, pode gerar viés no que diz respeito à realidade dos dados relatados a propósito do paciente.

- A organização das informações nem sempre segue a estrutura DAR. Por exemplo, o valor do resultado da medição da pressão arterial pode ser classificado como dados ou como resultados, para o mesmo alvo : "risco de hipertensão".

- É difícil distinguir uma acção que devia ser considerada de uma acção que já tenha sido executada. Por exemplo : “deve permanecer sóbrio" ou "humidificação parada".

- Os resultados das acções levadas a cabo pela enfermeira, que são os verdadeiros marcadores do acompanhamento da evolução dos problemas encontrados, estão muitas vezes ausentes dos registos escritos. 
- A precisão da informação relatada varia muito inter-individualmente e intraindividualmente (qualitativa e quantitativamente). orientada parece difícil. 0 objectivo deste trabalho é avaliar a adaptação da transmissão orientada à actividade de passagem de turno das enfermeiras. Tendo isto em atenção, realizámos uma análise da actividade de transmissão escrita numa população de enfermeiras que usam este novo sistema de notação, relativamente à sua actividade de supervisão da transformação do estado dos pacientes. Demos relevância particular ao processo de filtragem da informação pertinente relativamente à evolução do paciente.

- A transmissão orientada é usada ? Como?

- Até que ponto este formato escrito contém e preserva traços da actividade real de acompanhamento das enfermeiras (diagnósticos, prognósticos, riscos, incidentes, regulações)?

- Inversamente, que informações, originadas na actividade da enfermeira, não figuram nas transmissões?

- Quais são os processos cognitivos postos em prática durante a escrita da transmissão ? Qual é a função desta transmissão orientada comparativamente com a transmissão oral ? Da resposta a estas questões

\section{Método}

Dadas as dificuldades acima enunciadas, que traços significativos da actividade da enfermeira devem estar contidos na transmissão orientada? E, especificamente, será que estas irão preservar traços do diagnóstico de enfermagem, que se revela crucial no que diz respeito ao acompanhamento do paciente? A testagem desta hipótese requer que possamos comparar o conteúdo e forma dos documentos escritos com o conteúdo $\mathrm{e}$ forma das outras actividades da enfermeira no que diz respeito a pacientes que foram o objecto desses conteúdos escritos : particularmente, o conteúdo das transmissões orais e o conteúdo dos conhecimentos e representações da enfermeira, para cada paciente presente e resultados da actividade que precede a passagem de turno. A partir desta comparação, é possível deduzir tanto a existência de traços (escritos e nomeados) da actividade da enfermeira, como a natureza dos objectivos do acompanhamento realmente implementados para a realização deste documento profissional escrito. De facto, no momento da redaç̧ão da transmissão no novo formato, a enfermeira deve fazer um "cálculo" de modo a escolher, e depois transformar, e pôr em palavras os produtos de uma selecção da informação, sendo este "cálculo" dependente das representações memorizadas pelas enfermeiras no decorrer da sua actividade e durante a transmissão oral (esta última sendo, geralmente, efectuada previamente), dos constrangimentos ligados aos potenciais destinatários do registo escrito, e dos constrangimentos inerentes à actividade de redacção.

\subsection{População}

21 Solicitámos 9 enfermeiras que realizassem quotidianamente documentos de transmissão escrita orientada, tendo em conta uma variável que pudesse revelar-se sensível a esta actividade de transmissão, que é o facto de terem adquirido experiência. 
A distribuição foi a seguinte : 3 peritas, reconhecidas pelos seus pares pela qualidade das suas transmissões (tendo pelo menos 10 anos de experiência em diferentes Serviços), quatro principiantes (entre um e três anos de experiência em diferentes Serviços) e duas profissionais com um estatuto "intermédio" (mais de 3 anos de experiência em diferentes Serviços), mas analisadas como sendo experientes. Três Serviços diferentes foram analisados (medicina, neurologia e nefrologia) que eram comparáveis face àna gravidade das patologias encontradas (operações).

\subsection{Démarche e procedimento}

22 Seguimos uma démarche em 3 fases cronológicas, apresentadas na Tabela 2. Esta démarche baseia-se no estabelecimento de uma relação (comparação) entre a actividade real de cada enfermeira em saída de turno (com cada paciente), observada momentos antes das transmissões orais e escritas da passagem de turno, para os mesmo pacientes, durante o ciclo de trabalho. As enfermeiras a entrar no turno, beneficiárias desta transmissão, tinham estado ausentes entre 1 a 3 dias.

Tabela 2 : Metodologia e cronologia da análise da actividade de transmissão escrita.

\begin{tabular}{|c|c|c|c|c|}
\hline Evolução & Fases & Objectivos & $\begin{array}{l}\text { Processo } \\
\text { Estudado }\end{array}$ & Resultado/ Filtragem \\
\hline \multirow{3}{*}{ 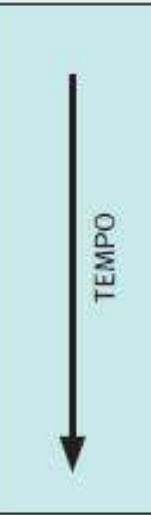 } & $\begin{array}{l}\text { Fase } \mathbf{1} \text { - Análise da } \\
\text { actividade anterior à } \\
\text { transmissão escrita } \\
\text { (70 pacientes, } 9 \\
\text { enfermeiras) }\end{array}$ & $\begin{array}{l}\text { Representaçōes } \\
\text { referenciais } \\
\text { individuais (RR), } \\
\text { previamente memo- } \\
\text { rizadas para cada } \\
\text { paciente }\end{array}$ & \multirow{3}{*}{ 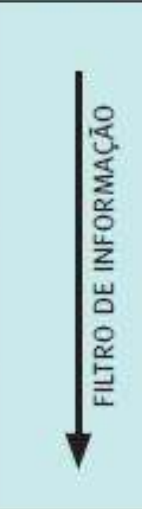 } & $\begin{array}{l}\text { Conhecimento e } \\
\text { representação de } \\
\text { referência (RR) }\end{array}$ \\
\hline & $\begin{array}{l}\text { Fase } \mathbf{2} \text {-Análise das } \\
\text { transmissões orais }\end{array}$ & $\begin{array}{l}\text { Informaçăo comu- } \\
\text { nicada durante a } \\
\text { transmissão oral } \\
\text { (TO) }\end{array}$ & & Comparação RR e TO \\
\hline & $\begin{array}{l}\text { Fase } 3 \text {-Análise } \\
\text { das transmissões } \\
\text { escritas }\end{array}$ & $\begin{array}{l}\text { Produção escrita } \\
\text { (PE) Informaçōes } \\
\text { e processos de } \\
\text { transcriçäo }\end{array}$ & & $\begin{array}{l}\text { Comparação RR, } \\
\text { TO e PE }\end{array}$ \\
\hline
\end{tabular}

O objectivo da primeira fase (tabela 2) era de constituir uma base de conhecimentos e representações referenciais relativamente ao conteúdo do acompanhamento de cada paciente, por cada enfermeira. Esta referência reflectia as representações previamente memorizadas para cada paciente, que cada enfermeira dispunha no momento de elaboração da transmissão oral e depois da transmissão escrita. Esta fase 1 foi realizada com uma análise prévia da actividade. Tratava-se de observações directas e registos feitos em situação: fizemos observações directas das acções, comportamentos e interacções de tratamento de cada enfermeira em situações reais, acompanhadas por registos áudio (com microfones sem fios) de cada interacção (com o paciente ou um colega) para cada enfermeira (num total de 81 horas). Todas as acções de cada enfermeira foram registadas, a passagem de turno anterior ao ciclo de actividade, as interacções com cada paciente, a passagem de turno posterior ao ciclo de actividade, oral e escrita. Estas observações e gravações foram depois integralmente retranscritas. Registámos com precisão as categorias de tratamentos associadas ao objectivo de cada 
aç̧ão da enfermeira: distribuição e toma de medicamentos, medição da pressão arterial, pedidos de informação, tratamento diário (mudança de pensos) e os conteúdos das informações trocadas com o paciente.

Foram seguidas por uma entrevista individual relativamente às representações memorizadas, conduzida logo após as observações directas. 0 objectivo deste momento de recolha de dados era transcrever o mais exaustivamente possível as representações e conhecimentos memorizados pela enfermeira relativamente à patologia e à evolução de cada paciente. Foi pedido às profissionais que distinguissem, por um lado, as representações anteriores ao dia de observações, e, por outro lado, as resultantes do período de observação. Esta entrevista teve lugar dois dias após as observações. De modo a facilitar a recuperação das representações para cada paciente, as enfermeiras dispunham dos documentos respeitantes a cada paciente (fichas de tratamento e prescrições) e as notas escritas das gravações feitas durante a observação precedente. Apesar dos dados gravados constituírem material rico para uma análise detalhada, a exploração dos dados desta fase não correspondia a uma análise completa da actividade que precede a passagem de turno mas é sobretudo um suporte que permitia, em seguida, recolher rigorosamente as representações das enfermeiras relativas aos pacientes. Esta redução é bem mais adequada aos objectivos limitados de comparação deste estudo.

A segunda fase tinha por fim a análise das transmissões orais de cada enfermeira observada relativamente aos 70 pacientes que as profissionais tinham a cargo durante a actividade precedente (fase 1). A repartição destes doentes era a seguinte : 23 para o grupo das principiantes, 22 para o grupo das experimentadas e 30 para as peritas. 70 passagens de turno foram gravadas, para o conjunto dos pacientes e enfermeiras da amostra. Os enunciados resultantes das retranscrições integrais foram em seguida analisados.

A terceira fase referia-se às transmissões escritas. Tinha por objectivo analisar o conteúdo e o processo de produção das transmissões para os mesmos 70 pacientes, pela 9 enfermeiras. Estávamos particularmente interessados nos traços da actividade de acompanhamento da nfermeira por cada paciente, e nos mecanismos usados para transcrição desses traços no âmbito da estrutura formal do DAR. 70 transmissões escritas foram recolhidas, transcritas integralmente e depois analisadas, correspondendo aos mesmos doentes das observações e das transmissões orais. Em seguida, com o intuito de recolher as informações respeitantes às regras da escrita e ao processo de produção dos documentos escritos, conduzimos, para cada documento, no dia seguinte à transmissão, e para cada enfermeira, uma entrevista de explicitação, pela enfermeira, a propósito de cada uma das transmissões que tinha escrito. Esta técnica de tipo protocolo verbal, adaptada de Bisseret, Sébillote e Falzon (1999), foi conduzida com o suporte escrito de cada documento, colocado na frente de cada enfermeira, para cada transmissão e teve a duração média de 2 horas por profissional. Os critérios de análise dos dados recolhidos pelas técnicas usadas em cada fase serão então descritos na apresentação de resultados.

Finalmente (última coluna da Tabela 2), os dados recolhidos nas 3 fases da nossa démarche foram postos em relação. 0 propósito desta comparação era o de precisar o processo de "filtragem" da informação, pela mesma enfermeira, começando pelas representações de referência (RR), as transmissões orais (TO) e as produções escritas (PE). Obviamente, as trocas de informações e as interacções não podem ser reduzidas a 
este processo de filtragem expresso na forma de "equação" na tabela 2. Contudo, o estudo deste processo de filtragem constitui uma dimensão importante para a análise da informação finalmente seleccionada e retida na transmissão escrita.

\section{Resultados}

\subsection{Fase 1 - A análise das observações : as representações prévias de referência}

O propósito deste trabalho estava centrado no processo de produção de documentos escritos. Como consequência, o nosso objectivo ao descrever os resultados desta primeira fase não era o de fornecer uma apresentação detalhada sobre os dados recolhidos nas 81 horas de observação das profissionais. Tratava-se de constituir uma base de representações de referência para cada paciente, de modo a permitir uma melhor compreensão da natureza e filtro das informações presentes nas transmissões escritas, que serão analisadas em detalhe na fase 3. Iremos limitar-nos, portanto, em apresentar os resultados desta primeira fase, numa exposição das actividades efectuadas, por um lado, e na extensão (quantitativa) dos conhecimentos memorizados, por outro, e finalmente, das temáticas e principais fontes de representações de referência relativamente a cada paciente, compreendendo as representações das situações anteriores à passagem de turno das profissionais.

Iremos fazer uma breve referência aos resultados das observações e depois os das entrevistas.

As actividades observadas foram as seguintes :

- As sequências dos tratamentos planeados, de acordo com um horário preciso : tirar amostras de sangue, verificar a pressão arterial, medicamentos, injecções.

- Tratamento individual ligado à evolução do estado do paciente: ajuda com a higiene, preparação pré-operatória, mudança de pensos, conforto.

- Actividades relacionadas com tratamentos de regulação não previstos : mudança no estado do paciente, resultados de exames.

- Interacções verbais com cada paciente, realizadas concomitantemente com o tratamento referido previamente, e mais focalizadas no vivido e relação com o paciente.

- Interacções com colegas e acções levadas a cabo fora do quarto dos pacientes (fichas a ser preenchidos, por exemplo).

- Actividades de transmissão das informações, orais e escritas, durante a passagem de turno. Estas últimas duraram, no mínimo, 30 minutos em cada passagem de turno. As transmissões orais eram geralmente colectivas, as escritas, individuais. A transmissão escrita era realizada para cada paciente antes da transmissão oral em 7 das 9 enfermeiras, durante o tratamento para 1 enfermeira e após a transmissão oral para 1 enfermeira. Também observámos uma grande variação na ordem da escrita das informações : algumas enfermeiras começavam pelos alvos antes de os desenvolver, outras começavam com a informação e depois escreviam o alvo. Umas enfermeiras liam o documento escrito anterior, enquanto outras, a maioria, não o faziam.

31 Assim, as representações memorizadas pelas enfermeiras eram o resultado das seguintes fontes de actividade :

- As actividades acima observadas e registadas. 
- O registo de informações verbais e não-verbais : visuais e proprioceptivas.

- As acções levadas a cabo que eram mais frequentemente resultado de prescrição médica.

- Acções de reajuste e regulação de um disfuncionamento no paciente.

A amplitude dos registos de informação pelas profissionais, obtida através da frequência das interaç̧ões (verbais ou nãoverbais) com pacientes, que é um (dos) indicador(es) relacionados com a quantidade de conhecimentos prévios, memorizado para cada paciente, difere grandemente em função do nível de experiência. De facto, o número médio de interacções por paciente é significativamente superior nas peritas (7.9 para 238 interacções com 30 pacientes) do que nas principiantes (5.5 para 127 interacções com 23 pacientes) e nas profissionais experientes (4.6 para 102 interacções com 22 pacientes) (Chi2 $=20.91, \mathrm{p}<.01)$. Sendo a taxa de interacção superior nas peritas, podemos supor que os conhecimentos previamente memorizados são mais e/ou mais precisos entre estas profissionais. Claro que a quantidade de conhecimento (e interacções) não é necessariamente indicativa da sua pertinência, nem da sua função ou conteúdo. Mas estudos em ergonomia cognitiva, relativamente ao diagnóstico em Medicina, mostram que este indicador de quantidade é de grande utilidade. Quantidade, e acima de tudo flexibilidade das representações operativas, constituem dimensões críticas na competência em Medicina e na prestação de cuidados (Raufaste, 2001).

Quais são as representações de referência que resultam da entrevista? Os dados verbais resultantes deste momento foram transcritos para cada enfermeira. Categorizámos, então, cada enunciado (proposição ou grupo de proposições ligados a um tema), em função do tipo de fonte das informações a que diziam respeito. Estas fontes (F) são ao todo 7 :

- F1 - Interacções verbais com o paciente (ex. "para o tratamento das 14h00, eu disse-lhe “ olá ", ele não respondeu... é um modo de avaliar a consciência deles... para alguém que deveria estar melhor, achei que ele não respondeu muito").

- F2 - Observação dos sinais clínicos e do comportamento durante as interacções verbais ou não-verbais (ex. "quando o levei para a balança, senti que ele não queria puxar o tripé do soro, isto incomoda-o").

- F3 - Novas informações no momento da passagem de turno (ex."a enfermeira da noite disseme... que ela tinha arrancado o soro").

- F4 - Conhecimentos anteriores ao dia da observação (ex. "ela tinha um problema de dor torácica, ... fez um electrocardiograma, um teste cardíaco que não tinha mostrado nada").

- F5 - Execução da prescrição médica (ex. "eu estava responsável pela sua vigilância depois do arteriografia... pressão arterial normal, pulso bom").

- F6 - Patologia intrínseca do paciente (ex. "ela foi apresentada como etílica com 3 gramas...").

- F7 - Acções autónomas (ex. "em relação às instilações dele, pedi que ele fizesse uma lavagem bucal").

Esta categorização servirá como base de referência na análise das informações contidas nas transmissões orais e depois nas escritas.

\subsection{Fase 2 - As transmissões orais}

Qual o conteúdo das transmissões orais ? Esta é a questão à qual tentámos responder através das análises conduzidas à amostra de 70 transmissões orais. Para o fazer, dividimos cada transmissão em unidades menores : a vez de falar, o enunciado e a 
sequência. A vez de falar é o indicador geral da densidade da transmissão. Gravámos 617 "vezes de falar" no conjunto total dos pacientes, ou seja, uma média de 8.1 vezes por paciente. $\mathrm{O}$ enunciado corresponde a uma unidade completa de informação sobre um tema, semelhante a uma proposição. Uma sequência é composta por um grupo de enunciados coerentes relativos ao mesmo tema. Constitui um bom indicador do objectivo procurado nos temas abordados por via dos enunciados.

\subsubsection{Os temas abordados nos enunciados, durante as interacções}

Tabela 3 : Metodologia e cronologia da análise da actividade de transmissão escrita.

\begin{tabular}{|c|c|c|}
\hline Temas de referência & $\%$ & Exemplo de categorização* \\
\hline Prescrição Médica & 34 & \multirow{9}{*}{$\begin{array}{l}\text { "Pelo contrário, a Sra. S (identidade**) que foi ope- } \\
\text { rada a um hematoma crónico subdural (diagnóstico } \\
\text { médico) não está assim tão mal (sinal clínico geral). } \\
\text { Ela ainda está a soro (prescrição) e se ela come bem, } \\
\text { não haverá problema em pô-la a comer (comporta- } \\
\text { mento). Ela tem um défice neurológico (sinal clínico), } \\
\text { trata-se de uma senhora que é insulino-dependente } \\
\text { (patologia) que toma um dextro a cada } 4 \text { horas } \\
\text { (prescrição). " }\end{array}$} \\
\hline Comportamento & 18 & \\
\hline Sinais clínicos & 16 & \\
\hline Diagnóstico & 9 & \\
\hline Motivo & 6 & \\
\hline Identidade & 4 & \\
\hline Patologias & 4 & \\
\hline Organizaçâo geral & 4 & \\
\hline Diversos & 4 & \\
\hline
\end{tabular}

* Escolhemos um exemplo simples e compreensível. Em muitos casos, a grande quantidade de termos técnicos e especializados tornam a compreensão difícil para um não-profissional.

**A identidade corresponde simplesmente à enunciação do nome do paciente e não é gravada mais que uma vez (por transmissão) Tabela 3 - Repartição (em \%) de diferentes temas de referência dos enunciados das transmissões orais.

Registámos 1184 enunciados, em 70 transmissões, ou seja, uma média de aproximadamente 17 enunciados por transmissão. Classificámos cada enunciado em função do seu objecto, ou seja, o tema da informação abordada, relativa ao paciente. Os resultados quantitativos desta classificação estão registados na tabela 3 , assim como um exemplo de categorização efectuada.

Constatámos a predominância de 3 tipos de informação. Os que contêm a prescrição médica e a sua implementação, os que têm a ver com comportamentos e os que se relacionam com os sinais clínicos que aparecem. Estas duas últimas categorias, sinais clínicos e comportamento, representam $34 \%$ dos enunciados. Correspondem aos indicadores reais da actividade de supervisão da enfermeira e da sua gestão de riscos. De facto, estes indicadores (particularmente os sinais clínicos) relacionam-se com modificações e mudanças no estado do paciente, a partir de uma base de conhecimentos estruturados pelo diagnóstico médico inicial, a prescrição e o motivo 
para hospitalização. Por outro lado, estes indicadores parecem ser sensíveis à experiência. As enfermeiras peritas exprimem mais frequentemente enunciados ligados ao surgimento dos sinais clínicos ou comportamentos (40\%) que as principiantes ( $29 \%)$ ou enfermeiras experientes (31\%). Inversamente, as principiantes têm primeiro em conta a prescrição médica ( $40 \%$ ), quando comparadas com as peritas $(32 \%)$. Os outros tipos de enunciado (identificação do paciente, motivos para hospitalização, organização) estavam igualmente divididos entre os níveis de experiência. Resumidamente, o estudo dos enunciados mostra que a transmissão oral abrange uma função de troca de representações operativas das mudanças de estado (sinais clínicos e comportamentos) e das suas evoluções possíveis no paciente.

\subsubsection{Objectivos das enfermeiras nas sequências de troca de informação}

Cada sequência (247 no total) caracterizava-se de acordo com 3 critérios. $O$ primeiro dizia respeito à natureza da situação descrita, que podia ser normal (contendo, por exemplo, o enunciado relativo à prescrição) ou mostrar um disfuncionamento no estado do paciente (mudança do estado ou do comportamento do paciente). 0 segundo critério relacionava-se com o assunto abordado nos seis temas: prescrição médica, patologia conhecida do paciente, efeitos da prescrição, comportamentos, sinais clínicos. O terceiro critério concerne o nível de regulação da situação descrita. Quatro níveis foram definidos : regulação realizada, regulação a ser realizada, fracasso da regulação, ausência de regulação. Diz-se que a regulação foi realizada quando a enfermeira indicava que, após a acção remediativa ou ajustamento da prescrição, o paciente recuperava o estado anterior à regulação. No caso da regulação a ser realizada, a transmissão continha a solução pertinente para o paciente, assim como o procedimento a seguir, mas a acção correspondente ainda não tinha sido realizada no momento da passagem de turno. Um fracasso na regulação correspondia à situação onde, depois de um disfuncionamento ter surgido no estado do paciente, as várias soluções remediativas tentadas tivessem falhado até a altura da passagem de turno. Finalmente, a ausência de regulação correspondia à situação onde as acções reguladoras a ser realizadas não o tinham sido (ou não podiam mais sê-lo). Seguem-se dois exemplos destas situações : um disfuncionamento a regular - "ela tem um cateter na mão. Enrolado com uma fita. Deve ser vigiada uma vez que ela o tirou, ela já tem tirado cateteres, ela não tem estado muito presente, eu diria apática"; uma ausência de regulação (ou fracasso) : "tem de beber, eu não o fiz o suficiente". 
Figura 1 - Repartição (em \%) das sequências de transmissão oral por temas (Patologia, Prescrição médica, Efeitos da prescrição, Comportamentos, Sinais clínicos) em função do tipo de situação (normal ou em disfuncionamento).

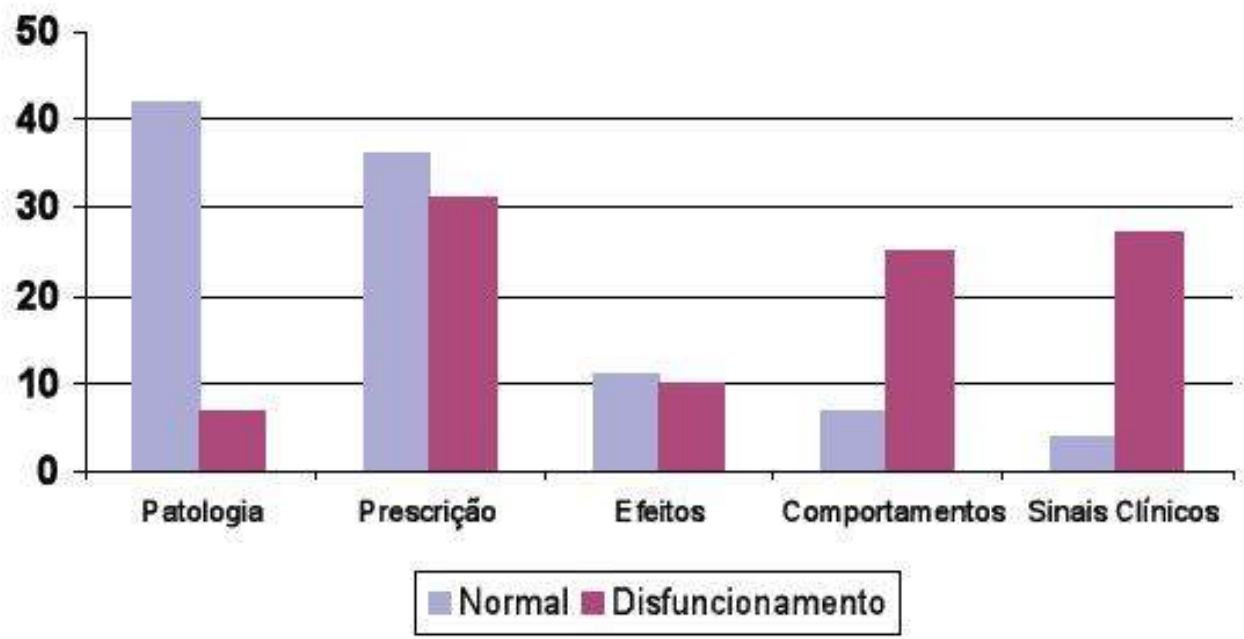

Das 247 sequências analisadas, 49 \% diziam respeito a uma situação normal, contra 51 \% que se relacionavam com um disfuncionamento. Relatamos, na figura 1, a repartição das sequências por tema e em função do tipo de situação (normal ou não).

Evidenciou-se que as taxas de disfuncionamento mais altas diziam respeito a 3 indicadores : as prescrições, os sinais clínicos e os comportamentos. Enquanto que um disfuncionamento relacionado com a prescrição pode corresponder, por exemplo, a um ajustamento individual da prescrição ao paciente, as categorias sinais clínicos e comportamentos eram indicadores críticos próprios às situações de disfuncionamento do estado de saúde do paciente que apareciam nas transmissões orais. É a regulação destes disfuncionamentos, não necessariamente ligada à prescrição, que está no centro das trocas da transmissão oral. A repartição das categorias de disfuncionamentos parece variar segundo o nível de experiência, tal como mostra a Figura 2.

Figura 2 - Repartição dos objectos de disfuncionamento segundo o nível de experiência

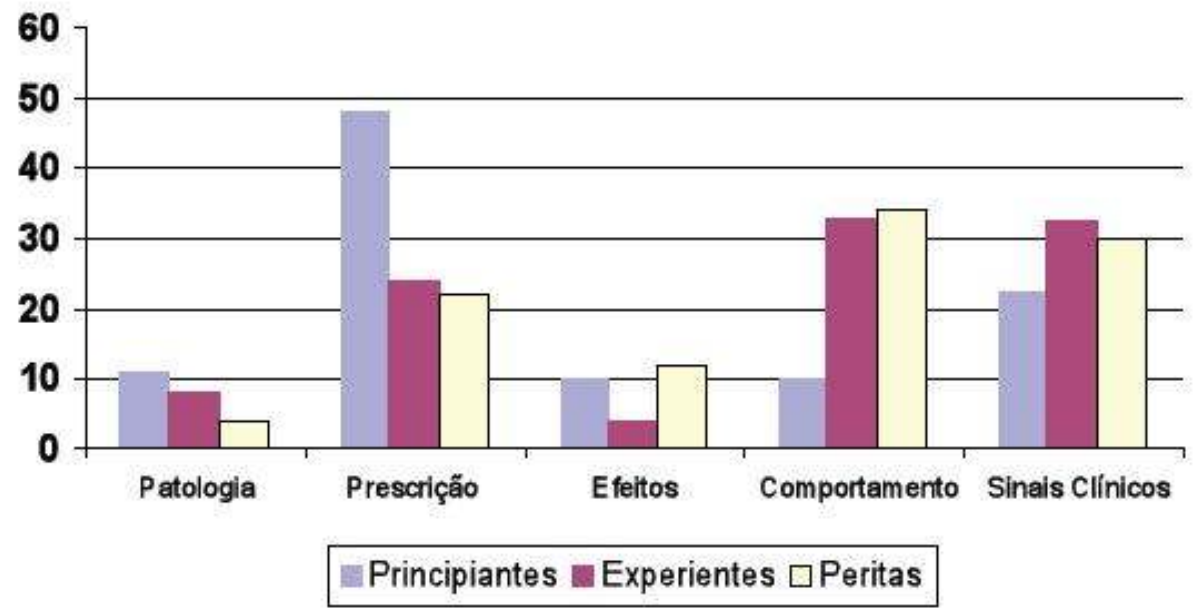


As peritas, assim como as profissionais experientes, trocaram muito mais informações ligadas aos sinais clínicos e aos comportamentos do que as principiantes, mais centradas na prescrição. Ora, as informações pertinentes para a passagem de turno são sobretudo as primeiras, que constituem traços da actividade de acompanhamento e de supervisão do paciente, prestada pela enfermeira. Deve notar-se que esta estatística indica uma tendência, uma vez que os dados relativos aos 3 níveis de experiência não se relacionam com as mesmas situações de patologia.

\subsubsection{Regulação enquanto desafio nas transmissões orais}

Quais os níveis de regulação expressos nas transmissões orais? Indicámos acima os 4 estádios possíveis de regulação. A repartição das sequências das transmissões orais compreendendo a evocação de um disfuncionamento, em função destes 4 níveis, é apresentada na tabela 4.

Tabela 4 : Distribuição dos diferentes níveis de regulação referidos durante a transmissão oral.

\begin{tabular}{|c|c|}
\hline Nivel de regulação & Frequências em \% \\
\hline Regulação realisada & 29 \\
\hline Regulação a realisar & 12 \\
\hline Fracasso da regulação & 10 \\
\hline Ausência de regulação & 10 \\
\hline Tabela 4: Distribuição dos diferentes níveis de regulação referidos durante a transmissão oral. \\
\hline
\end{tabular}

Parece, assim, que $51 \%$ dos disfuncionamentos ainda não foram regulados. A sua evocação durante a transmissão oral permite orientar a actividade de supervisão da enfermeira que recebe a transmissão. Enfim, os disfuncionamentos ainda por regular, foram mais frequentemente abordados pelas peritas ( $40 \%$ contra $15 \%$ no caso das principiantes e $20 \%$ no caso das enfermeiras experientes). A perita parece antecipar as regulações de disfuncionamentos presentes no estado do paciente, sobretudo a partir de sinais clínicos e comportamentais. Podem ainda ser discutidos, durante a passagem de turno, ao longo da interacção, os modos de regulação a realizar.

Em suma, a análise do conteúdo da transmissão oral permitiu-nos evidenciar a sua função enquanto troca pragmática relacionada com a evolução do estado do paciente, a partir de indicadores específicos para as profissionais, respeitantes aos sinais clínicos e às variações do comportamento. Um dos desafios da passagem de turno reside na gestão e resolução dos problemas de disfuncionamento e das regulações ainda por realizar. Seria interessante, mas fora dos limites quantitativos de um único artigo, aprofundar os tipos de disfuncionamento regulados e aqueles não-regulados, comparandoos, por exemplo, com os dados da análise prévia da actividade (fase 1).

Em que medida as informações pertinentes para a supervisão do estado do paciente, registadas durante as transmissões orais (sinais clínicos, comportamentos, disfuncionamentos a regular) estavam presentes nas transmissões orientadas, e de que 
modo? Que informações adicionais à transmissão oral, ou subtraídas desta, contêm os registos escritos ? Como foram produzidos e utilizados os documentos da transmissão orientada, em comparação com as informações orais? Este é o objecto das análises que se seguem, centradas nos documentos de transmissão escrita.

\subsection{Fase 3 - Documentos de transmissão escrita orientada}

Analisámos o corpo de 70 transmissões escritas. Uma série de exemplos destas transmissões escritas é fornecido na figura 3. Inicialmente, iremos apresentar os resultados das análises dos documentos escritos em si, e seguidamente iremos observar os dados provenientes dos protocolos verbais recolhidos, a propósito da redacção destes documentos escritos.

Figura 3 - Exemplo de uma ficha de transmissão escrita orientada usado na passagem de turno

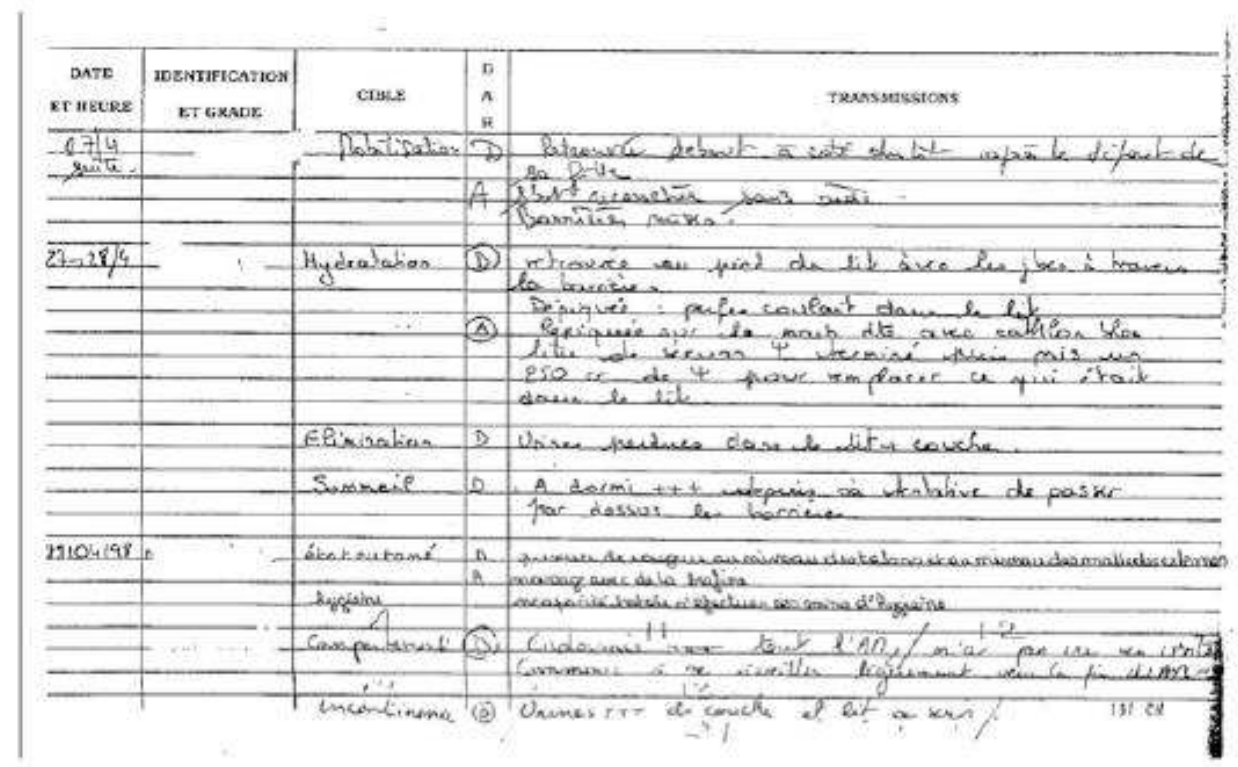

\subsubsection{Selecção das informações contidas nos documentos de transmissão escrita} e uso da formulação em DAR

Estudámos cada documento de transmissão de acordo com a presença dos elementos prescritos : em $1^{\circ}$ lugar a presença de um alvo e selecção da informação no formato DAR, seguido de uma análise da natureza dos alvos e da estrutura escrita. Processámos 115 alvos como mostrado na tabela 5 . 
Tabela 5 : Repartição (em \%) dos alvos em função da sua estrutura (Dados, Resultados, Dados + Acções, Dados + Acções + Resultados, Não classificados, Mistos).

\begin{tabular}{|c|c|c|c|c|c|c|}
\hline Selecção & Dados & DA & $\begin{array}{c}\text { Não classi- } \\
\text { ficados }\end{array}$ & DAR & $\mathbf{R}$ & $\begin{array}{c}\text { DARA/ } \\
\text { DRA }\end{array}$ \\
\hline$\%$ & 26 & 23 & 20 & 12 & 12 & 7 \\
\hline
\end{tabular}
enunciados. Um enunciado corresponde a uma proposição coerente e/ou a uma expressão mais pequena que a proposição, mas contendo uma unidade semântica. Um enunciado correspondia portanto, a uma unidade funcional do documento de transmissão escrita. Por exemplo, o enunciado "ainda não sabemos se ela precisa de uma transfusão ou não", compreende várias (duas) proposições, enquanto que o enunciado "incontinente" não constitui uma. Mas ambos enunciados exprimem uma unidade funcional de informação médica para a transmissão. Ao usar esta separação, registámos 354 enunciados abrangendo 115 alvos encontrados nos 70 documentos de transmissão escrita (correspondendo às situações observadas durante a análise prévia do trabalho), isto é, uma média de 5 enunciados por transmissão (ou seja, por paciente) e 3 enunciados por alvo.

50 A repartição de enunciados de acordo com os critérios Dados ou Acções ou Resultados mostrou que predominaram as informações relativamente aos dados (44\%) comparativamente às acções $(21 \%)$ ou aos resultados (15\%). Restaram $20 \%$ dos enunciados que foram impossíveis de classificar dentro destas 3 categorias. Os dados parecem, portanto, constituir a base informacional para a passagem de turno.

\subsubsection{A natureza dos alvos}

51 Dos 70 documentos de transmissão escrita, $97 \%$ incluíram um (ou mais) alvos. 0 número médio de alvos por paciente era de 1.6 (num mínimo de 1 e máximo de 5 alvos para um único paciente). Este resultado significa que as enfermeiras que participaram no estudo estavam significativamente empenhadas na utilização do novo formato de documento de transmissão escrita.

52 Poucos foram os alvos recorrentes comuns aos 3 Serviços ("risco de infecção, comportamento, dor, eliminação, exames, admissão, alta, prognóstico"). Existiam mais alguns que eram comuns a dois Serviços ("mobilização, hipertermia, ferimento cutâneo, pressão arterial, alimentação, respiração, vigilância, hemo-dinâmica"). Alvos próprios a um Serviço relacionavamse com a especificidade das patologias tratadas 
nesse Serviço médico (em medicina: "confusão, dispneia", por exemplo; em nefrologia: "educação para a diálise", por exemplo; em neurocirurgia: "ligadura craniana", por exemplo).

Tendo em conta esta disparidade, realizámos uma classificação temática dos alvos. Analisámos uma amostra de 1258 alvos. Esta amostra correspondia ao corpo de 70 documentos de transmissão escrita realizados no dia em que a actividade de enfermagem foi observada, aos quais se adicionaram os documentos de transmissão escrita do dia em que o paciente foi admitido, até ao dia da observação. Os critérios de classificação usados, assim como a repartição dos alvos de acordo com cada categoria, são apresentados na tabela 6.

Tabela 6 : Repartição (em \%) dos tipos de alvo, de acordo com as categorias

\begin{tabular}{|l|c|}
\hline \multicolumn{1}{|c|}{ Critérios usados para categorização de alvos } & Repartição em \% \\
\hline $\begin{array}{l}\text { Fisiologia (relativamente a um evento fisiológico que ocorreu: } \\
\text { corrimento nasal, dispneia, vó mitos, dor de cabeça, etc.) }\end{array}$ & 57 \\
\hline Fase de hospitalização (admissão, consulta, alta, relatório, bloco, etc.) & 12 \\
\hline $\begin{array}{l}\text { Acções técnicas realizadas/a realizar (mobilização para tratamento, } \\
\text { ligadura craniana, etc.) }\end{array}$ & 10 \\
\hline Psicologia (confusão, recusa de tratamento, etc.) & 9 \\
\hline Patologia do paciente (insuficiência renal, diabetes, etc.) & 3 \\
\hline Equipamento técnico (para soros, câmara implantável, etc.) & 3 \\
\hline $\begin{array}{l}\text { Tratamento em realização (injecção de fraxiparina, educação para a } \\
\text { diálise, etc.) }\end{array}$ & 1 \\
\hline Diversos & \\
\hline Tabela 6: Repartição (em \%) dos tipos de alvo, de acordo com as categorias & \\
\hline
\end{tabular}

Pode-se observar que, em primeiro lugar, são os eventos fisiológicos novos, depois as fases de hospitalização, acções técnicas e por fim os aspectos psicológicos, que constituem os conteúdos dos alvos. Quais são as funções destas informações para a passagem de turno? Que indicações fornecem no que diz respeito à regulação do acompanhamento do paciente, a realizar a seguir à passagem de turno ? De modo a precisar este aspecto, realizámos dois tipos de análises. Primeiro, centrámo-nos nas formas sintácticas e verbais usadas pelas profissionais na redacção dos seus escritos. Depois, procurámos, de modo sistemático, traços da actividade da enfermeira (diagnósticos, regulações, recomendações). Estas análises parecem-nos poder constituir-se como indicadores da actividade realizada, dos diagnósticos e das acções de regulação propostas. 


\subsubsection{Função das transmissões orientadas para a passagem de turno}

O propósito desta análise é o de precisar as funções das informações contidas nos documentos de transmissão escrita. Ao estudar inicialmente a sintaxe, pudemos distinguir três categorias. A primeira, sujeito - verbo - complemento (SVC), correspondia à sintaxe canónica de como a frase era escrita. A segunda, tinha uma forma relativamente abreviada, verbo - complemento (VC). Finalmente, a terceira constituía uma restrição sintáctica limitada à ordem das palavras (OP). Esta última categoria não só correspondia ao uso de formas elípticas, mas também a uma sintaxe restrita, semelhante à linguagem restrita descrita por Falzon para a transmissão oral $(1989,2004)$. A repartição dos enunciados nos documentos de transmissão escrita, de acordo com estas categorias, mostrou que a estrutura SVC representava $22 \%$ dos enunciados ; a estrutura VC $43 \%$; e a estrutura OP $35 \%$. Estes dados indicam que uma linguagem do tipo operativo, bem conhecida na transmissão oral (Falzon, 1989, 2004), foi aqui usada na escrita, muitas vezes restringida à ordem das palavras: "sacro vermelho, lateralização e fricção, fezes às 20 horas"). Para além disso, uma grande proporção de palavras técnicas eram adicionadas a estas restrições económicas, selectivas e eficazes, usadas entre peritas.

No que diz respeito às formas verbais, em segundo lugar, dividimos cada enunciado de acordo com o tempo verbal usado para a sua formulação. Os resultados desta divisão indicaram que a utilização do tempo passado era maioritária ( $47 \%$, passado, particípio passado), seguido do tempo presente (23\%) ou frases sem verbos (29\%). A utilização do tempo futuro é muito mais rara (6\% para o futuro simples, $6 \%$ para o imperativo). Estes resultados sugerem que as informações escritas são dirigidas para as acções passadas ou presentes (59\%) e/ ou para os dados, mas muito menos para as acções a realizar (6 a $12 \%)$, as antecipações, isto é, as regulações a ser levadas a cabo e disfuncionamentos a regular. Obviamente, as informações passadas são essenciais para a tomada de decisão de acções futuras. Contudo, estas decisões constituíram, tal como demonstrámos na nossa análise da transmissão oral, indicadores da actividade de acompanhamento do estado do paciente, dado pelas profissionais.

Em terceiro lugar, que traços da actividade de acompanhamento do paciente, podem ser encontrados nos documentos de transmissão escrita, em relação à escolha do alvo ? Notámos dois tipos de alvos. 0 primeiro está relacionado com a utilização de categorias provenientes de um modelo teórico, tradicionalmente ensinado durante a formação em enfermagem : "a teoria da necessidade". Este modelo usa uma categorização em termos das funções vitais gerais fisiológicas e psicológicas, como "respiração", "eliminação", e "comunicação". Os documentos escritos apresentados na figura 2 contêm esta lista: "mobilização, hidratação, eliminação, sono". Este tipo de alvo mais formal não fornece logo (em si mesmo), uma informação relacionada com o estado ou evolução do estado do paciente. $O$ segundo tipo de alvo é mais relacionado com uma variável da evolução do estado do paciente : "fadiga", "inapetência", "hipoglicémia". A distinção entre estes dois tipos de alvo pode aplicar-se tanto a alvos fisiológicos como psicológicos. Tal como os dados da tabela 7 mostram, os alvos do tipo necessidade parecem imperar no domínio fisiológico, e as variáveis tipo estado são massivamente reservadas para o domínio psicológico. 
Tabela 7 : Repartição (em \%) dos alvos tipo necessidade ou tipo estado de acordo com o seu domínio, fisiológico ou psicológico

\begin{tabular}{|c|c|c|}
\hline & Alvo do tipo necessidade & Alvo do tipo estado \\
\hline Domínio fisiológico & 55 & 45 \\
\hline Domínio psicológico & 2 & 98 \\
\hline $\begin{array}{l}\text { Tabela 7: Repartição (em \%) dos alvos tipo necessidade ou tipo estado de acordo com o seu } \\
\text { domínio, fisiológico ou psicológico }\end{array}$ \\
\hline
\end{tabular}

Para além disso, notámos que em $80 \%$ dos documentos escritos analisados, esta formulação de alvos que utiliza a nomenclatura das "necessidades" podia gerar uma ambiguidade semântica relativamente à coerência entre a informação fornecida pelo alvo e a fornecida pelos dados. Vejamos alguns exemplos. No documento seguinte: "mobilização (alvo). Após sair da cadeira, respirava melhor mas sofria de muitas dores nas costas (dados)", poderíamos pensar que o termo "mobilização" reenviava-nos a uma necessidade, é ambíguo, ou pouco adaptado para designar a informação importante relativa ao estado do paciente (correspondendo à instrução DAR ao alvo) que reside nas dificuldades respiratórias e não nas acções de mobilização realizadas. $O$ mesmo se aplica nos dois exemplos seguintes (retirados da figura 2) : no documento escrito "mobilização (alvo). Encontrado de pé ao lado da cama depois da filha ter saído (dados)", a informação crucial "encontrado de pé" não é definida de modo preciso pelo alvo. No documento escrito "Hidratação (alvo). Encontrado aos pés da cama com as pernas através da barreira. Tendo saído, o soro estava a correr para a cama (dados)", a informação descrita pelos dados é também reflectida ambiguamente no alvo "hidratação" (que corresponde a uma necessidade geral de água). Este tipo de ambiguidade pode ser interpretada como sendo devida ao facto das enfermeiras terem dificuldade em encontrar ou decidir por um alvo. Isto seria relativamente surpreendente no caso das profissionais peritas. Uma hipótese alternativa parece-nos plausível: poderia ser muito difícil descrever um alvo que reflictisse mudanças expressas pelos sinais clínicos e/ou comportamentos usando um termo genérico ou único. Neste caso, a formulação em termos genéricos, originada pela "teoria das necessidades" corresponderia a um uso adaptativo, deturpado, deste registo médico, correspondendo, portanto, a uma catacrese instrumental da linguagem (Rabardel, 1995) de modo a descrever problemas (ou as suas consequências) ocorridos no paciente : problemas ligados à mobilização, problemas ligados à hidratação, etc. Em suma, ao utilizar este tipo de formulações, estarão as profissionais a tentar adaptar-se à prescrição? Também pode acontecer que os profissionais não tenham conseguido construir uma representação clara e precisa da noção de alvo, prescrita no formato DAR. Estas duas alternativas reflectiriam ambiguidade na prescrição em si. Finalmente, os problemas de coerência entre alvos e dados eram muito mais frequentes quando o alvo designava uma necessidade $(87 \%)$ do que quando o alvo era formulado em termos da variável estado ( $52 \%)(\mathrm{Chi} 2=7.63, \mathrm{p}<.01)$. Ora, a variável estado tem melhor em conta a actividade da enfermeira. Mas acima de tudo, as ambiguidades referenciais que acabámos de elicitar, testemunham a dificuldade do uso do formato DAR. Os constrangimentos estruturais deste formato, parecem conduzir a transformações dos documentos escritos dificilmente compatíveis com as representações funcionais em 
termos de sinais clínicos e psicológicos, que constituem os indicadores de tratamento do paciente para as enfermeiras.

Os traços da actividade também se revelaram na natureza das informações desenvolvidas. A distribuição dos diferentes tipos de temas desenvolvidos nos documentos de transmissão baseados nos alvos, aproximam-se da distribuição constatada para as transmissões orais, tal como evidencia a tabela 8.

Tabela 8 : Repartição (em \%) dos temas no caso da transmissão oral e escrita

\begin{tabular}{|c|c|c|}
\hline Temas de referência & Transmissão oral & Transmissão escrita \\
\hline Prescrição mé dica & 34 & 20 \\
\hline Comportamento & 18 & 20 \\
\hline Sinais clínicos & 16 & 6 \\
\hline Diagnóstico & 9 & 0 \\
\hline Motivo para hospitalização & 6 & 0 \\
\hline Identidade & 4 & 0 \\
\hline Patologias (iniciais) & 4 & 8 \\
\hline Acçōes não prescritas & 4 & 2 \\
\hline Organização geral & 4 & \\
\hline Tabela 8: Repartição (em \%) dos temas no caso da transmissão oral e escrita
\end{tabular}

Observámos de novo grande sensibilidade à experiência na distribuição dos temas. Comportamentos, sinais clínicos e aç̧ões decididas no momento (fora da prescrição médica) são mais altas nos dois grupos mais experientes (respectivamente : 63,4 \% para peritas e $66 \%$ para as experientes) do que entre principiantes (36.5\%). A tendência era inversa no que diz respeito à prescrição médica, que aparecia mais entre as principiantes (50\%) do que entre as enfermeiras peritas (27.5\%) ou experientes (20\%).

\subsubsection{O desaparecimento das regulações durante as transmissões escritas}

61 Uma das funções da transmissão oral diz respeito à regulação de disfuncionamentos, particularmente os que não foram regulados ou que permaneciam por regular ( $51 \%$ dos disfuncionamentos). Nos documentos escritos, encontrámos exclusivamente regulações realizadas. Ora, os documentos de transmissão escrita não contêm nenhuma referência explícita aos disfuncionamentos por regular ou aos fracassos de regulação. Paradoxalmente, estas informações, directamente ligadas ao acompanhamento do paciente e à antecipação de riscos, foram objecto de uma filtragem entre a transmissão oral e escrita. Certos tipos de regulação, que podem ter sido discutidos durante a transmissão oral, podem não ser fáceis de explicitar no registo escrito, devido, por exemplo, a incertezas relativamente à situação a ser regulada e também a uma possível 
falta de informação fiável relativamente a uma regulação presentemente a decorrer. Uma análise mais aprofundada dos dados provenientes da análise da actividade de prestação de cuidados, anterior àquela por nós registada, poderia fornecer informação relevante para encontrar razões para este desaparecimento das regulações.

Em resumo, observámos que os documentos de transmissão escrita com o formato DAR não são adaptados às necessidades do pessoal de enfermagem. Eles contêm, contudo, um grande número de traços de actividade específica de acompanhamento do paciente, realizada pelas enfermeiras: evolução dos sinais clínicos, dos comportamentos, das acções autónomas não-prescritas. Mas uma filtragem importante é realizada no que diz respeito às regulações, um dos desafios mais importantes na transmissão oral. Para além disso, as informações descritas são relativamente diferentes, de acordo com o nível de experiência. Finalmente, os dois tipos de transmissão, escrita e oral, não parecem cumprir a mesma função; a transmissão escrita não veicula a mesma informação que a transmissão oral e não se relaciona necessariamente com o mesmo destinatário que a transmissão oral.

\subsubsection{Critérios de selecção na transmissão escrita}

Quais os critérios cognitivos envolvidos na selecção realizada na escrita? Isto é o que abordaremos ao expor, enquanto última análise, os resultados obtidos, a partir dos protocolos verbais de cada enfermeira, respeitantes a cada documento das suas transmissões escritas do ciclo anterior.

Durante a tarefa de explicitação individual (Bisseret, Sébillote \& Falzon, 1999), cada enfermeira tinha, à sua frente, os dois últimos documentos de transmissão escrita, assim como a transcrição da base de conhecimentos de referência, previamente analisada para cada paciente. Cada enfermeira tinha de responder a duas questões (padrão) para cada transmissão : "Como fez para seleccionar (escolher) as informações incluídas na transmissão ? (e assim sucessivamente para cada transmissão) e "como fez para decidir (optar) por não transmitir algumas das informações ?" O propósito desta prova era recolher as regras "explícitas" usadas durante a fase de redacção em si. Para cada transmissão, considerámos primeiro os mecanismos de selecção explicitamente referidos que eram comuns aos 3 grupos de enfermeiras e a cada nível de experiência. Depois, fizemos uma distinção mais precisa entre os factores de selecção positiva, correspondentes à informação que era retida, e finalmente entre os factores de selecção negativa, correspondentes à informação que era rejeitada. Em cada caso, uma única evocação explícita do critério era suficiente para que este fosse retido.

65 Em primeiro lugar, todas os profissionais indicaram a existência de uma fase de procura na memória, acompanhada, subsequentemente, por outras actividades. Mais especificamente, as peritas referiram usar os seguintes indicadores: "procurar na memória as informações do acompanhamento", "leitura dos documentos de transmissão anteriores" e "interacções com o paciente". As principiantes indicaram : "procurar na memória as informações", "as informações apresentam-se sob a forma de imagens". o pessoal experiente relatou: "procurar na memória as informações do acompanhamento", "leitura dos documentos de transmissões anteriores".

Durante esta fase, comum a todas, pode acrescentar-se que as principiantes evocavam principalmente as informações baseadas nos tratamentos prestados ("imagens"), e as 
peritas baseavam a sua avaliação, sobretudo, nas informações resultantes da supervisão do estado do paciente.

67 Em segundo lugar, registámos os critérios usados para a selecção de informações mais específicas, que as enfermeiras declaravam usar durante a fase de redacção em si da transmissão escrita, de acordo com cada nível de experiência. Os resultados são apresentados nas tabelas 9a (informação retida) e 9 b (informação rejeitada).

Tabela 9a : Critérios de selecção da informação a escrever, de acordo com o nível de experiência.

\begin{tabular}{|c|c|c|}
\hline Principiantes & Experientes & Peritas \\
\hline $\begin{array}{l}\text { Objectivo declarado da } \\
\text { selecção } \\
\text { - Prescrição do mé dico (a } \\
\text { realizar). } \\
\text { - Não repetir informação. } \\
\text { - Incorporar os "diagnósticos } \\
\text { de enfermagem". }\end{array}$ & $\begin{array}{l}\text { Objectivo declarado da } \\
\text { selecção } \\
\text { - Anotar e categorizar } \\
\text { dificuldades. }\end{array}$ & $\begin{array}{l}\text { Peritas } \\
\text { Objectivo declarado da } \\
\text { selecção } \\
\text { - Escolher conhecimentos } \\
\text { memorizados relativos ao } \\
\text { paciente, relacionados com } \\
\text { a evolução do seu estado. }\end{array}$ \\
\hline $\begin{array}{l}\text { Critérios de selecção } \\
\text { - Problema do paciente } \\
\text { (diagnóstico inicial). } \\
\text { - Aparecimento de um } \\
\text { problema nesse dia. } \\
\text { - Mudança durante o turno. } \\
\text { - Trocas de informação com } \\
\text { o médico no que diz respeito } \\
\text { à prescrição. } \\
\text { - Tarefas do turno não } \\
\text { realizadas, tendo em conta a } \\
\text { prescrição. } \\
\text { - Estado medido (fichas) da } \\
\text { patologia }\end{array}$ & $\begin{array}{l}\text { Critérios de selecção } \\
\text { - Informação não orientada } \\
\text { sob a forma de um relatório } \\
\text { (fichas, etc.). } \\
\text { - Evolução de um parâmetro } \\
\text { (incluindo fora do diagnósti- } \\
\text { co inicial). } \\
\text { - Informação complementar } \\
\text { comparada com o alvo } \\
\text { anterior (medições, sinais } \\
\text { clínicos) sob a forma de } \\
\text { resultados. }\end{array}$ & $\begin{array}{l}\text { Critérios de selecção } \\
\text { - Evolução nos dados clíni- } \\
\text { cos, quando comparados } \\
\text { com o último turno. } \\
\text { - Grande mudança na } \\
\text { prescrição acarretando um } \\
\text { risco vital (tratamento pelas } \\
\text { enfermeiras do próximo } \\
\text { turno). } \\
\text { - Informação assinalando } \\
\text { dúvidas no que diz respeito } \\
\text { ao efeito do tratamento. } \\
\text { - Resultados de exames } \\
\text { realizados. } \\
\text { - Acções autónomas } \\
\text { realizadas. }\end{array}$ \\
\hline
\end{tabular}


Tabela 9b : Critérios para rejeição da informação durante a fase de redacção.

\begin{tabular}{|c|c|c|}
\hline Principiantes & Experientes & Peritas \\
\hline $\begin{array}{l}\text { Fins declarados da informa- } \\
\text { ção rejeitada } \\
\text { - Evitar as repetiçōes (pre- } \\
\text { sentes noutros suportes). } \\
\text { - Informaçōes respeitantes a } \\
\text { uma tarefa prescrita planifi- } \\
\text { cada, não realizada (disfun- } \\
\text { cionamento não regulado ou } \\
\text { a regular). }\end{array}$ & $\begin{array}{l}\text { Fins declarados da informa- } \\
\text { ção rejeitada } \\
\text { - Evitar as repetiçōes (pre- } \\
\text { sentes noutros suportes). } \\
\text { - Informaçōes respeitantes a } \\
\text { uma tarefa prescrita planifi- } \\
\text { cada, não realizada (disfun- } \\
\text { cionamento não regulado ou } \\
\text { a regular). }\end{array}$ & $\begin{array}{l}\text { Fins declarados da informa- } \\
\text { ção rejeitada } \\
\text { - Evitar as repetições (pre- } \\
\text { sentes noutros suportes). } \\
\text { - Informações respeitantes a } \\
\text { uma tarefa prescrita planifi- } \\
\text { cada, não realizada (disfun- } \\
\text { cionamento não regulado ou } \\
\text { a regular). }\end{array}$ \\
\hline $\begin{array}{l}\text { Critérios específicos } \\
\text { - Problema do dia já } \\
\text { conhecido. } \\
\text { - "Hábitos de vida não trans- } \\
\text { missiveis em DAR". }\end{array}$ & $\begin{array}{l}\text { Critérios específicos } \\
\text { - Conhecimentos sobre o } \\
\text { paciente orientadores das } \\
\text { escolhas de uma estratégia } \\
\text { de relação. } \\
\text { - Acçōes a realizar durante o } \\
\text { turno seguinte não extraîdas } \\
\text { da prescriçăo médica }\end{array}$ & $\begin{array}{l}\text { Critérios específicos } \\
\text { - Dúvida sobre um problema } \\
\text { que implica um tratamento } \\
\text { diferente da prescrição } \\
\text { médica. } \\
\text { - Conhecimentos sobre o } \\
\text { paciente orientadores das } \\
\text { escolhas de uma estratégia } \\
\text { de relação. } \\
\text { - Discurso do paciente não } \\
\text { suficientemente preciso. } \\
\text { - Esquecimentos. } \\
\text { - Acções fora da prescrição } \\
\text { médica. }\end{array}$ \\
\hline
\end{tabular}

68 No que diz respeito à informação retida (Tabela 9a), parece que as enfermeiras principiantes seleccionavam mais facilmente informação orientada para a tarefa prescrita: prescrição médica, repetições, tarefas do turno não realizadas. As enfermeiras um pouco mais experientes pareciam apoiar, sobretudo, a sua selecção, na escolha de informações que estavam ausentes da transmissão anterior ou de outras fichas escritas existentes. As peritas faziam o mesmo, até um certo ponto. Mas estas pareciam principalmente seleccionar as informações relevantes a partir das representações memorizadas durante os turnos anteriores e, acima de tudo, da actividade realizada durante o ciclo de trabalho. Estas informações, relacionadas com um modelo de evolução do estado do paciente, construído através da actividade de supervisão e baseado em sinais clínicos e comportamentais que sejam explícitos, define e tem a ver com a dimensão do risco para o paciente : evolução dos dados clínicos, mudanças na prescrição, informação assinalando dúvidas no que diz respeito aos efeitos do tratamento.

No que diz respeito aos critérios usados para a rejeição da informação (tabela 9b), notámos o aparecimento de informação redundante nos três sub-grupos, mas também, e acima de tudo, das acções ou disfuncionamentos a regular ou não regulados. Para as peritas, parece que, logo que surgia uma dúvida (no que diz respeito aos sinais clínicos), a informação não era transcrita. Assim, os documentos de transmissão escrita não explicitavam as situações a regular, não reguladas ou para as quais subsistia uma dúvida importante. Por outro lado, eram as situações relativas à resolução de problemas que estavam no centro das trocas durante a transmissão oral. 


\section{Discussão e conclusão}

Durante uma démarche comparativa deas 3 fases da actividade das enfermeiras, compreendendo a actividade de prestação de cuidados, a transmissão oral e a transmissão escrita, realizámos uma avaliação ergonómica do uso de um formato de transmissão escrita recentemente prescrito : documentos de transmissão orientada em formato DAR. Neste estudo foram abrangidas 9 enfermeiras - peritas, experientes e principiantes - que trabalhavam com 70 pacientes em

713 Serviços médicos comparáveis. A análise mostrou que, por um lado, a forma destas transmissões escritas corresponde minoritariamente à estrutura prescrita DAR, e por outro, que as actividades habituais de regulação ou as que colocam problemas (dúvidas relativamente a um sintoma, fracasso na regulação), particularmente importantes para o turno seguinte, eram excluídas dos documentos escritos, apesar de terem constituído mais frequentemente a questão mais importante da transmissão oral. Ora, o diálogo na transmissão oral e os traços deixados pela transmissão escrita têm papéis diferentes no acompanhamento do paciente durante os diferentes turnos. Na passagem de turno, a transmissão oral e a escrita contêm traços do trabalho de supervisão das enfermeiras sobre o estado dos pacientes. Esta actividade de supervisão repousa na selecção, transmissão e discussão de indicadores específicos : modificações ou evolução dos sinais clínicos e comportamentos. Estes indicadores, sensíveis no que diz respeito ao nível de experiência, permitiam a prevenção e regulação de disfuncionamentos e, portanto, de riscos possíveis.

72 A partir do balanço dos dados recolhidos durante as três fases da análise realizada, preparámos uma síntese sob a forma de uma modelização da actividade de transmissão escrita aqui estudada. Esta modelização foi inspirada, por um lado, em modelos de produção escrita elaborados em psicologia cognitiva que nos pareceram extremamente compatíveis com os nossos resultados (Fayol, 1997) e por outro, nos resultados da nossa análise das notas de transmissão escrita. 0 modelo proposto na figura 4 compreende 3 etapas. Durante a primeira, o objectivo da enfermeira é escolher um alvo. Para o fazer, procura informação relevante e pertinente na memória, relativa à evolução do paciente e às actividades levadas a cabo durante o período anterior. Esta procura pode ser realizada em paralelo com outro tipo de tratamento que seja mais semelhante à selecção da informação com diferentes critérios. De facto, é preciso escolher um dado ou uma nova acção significativa como alvo para regular o tratamento do paciente, comparando-a, não só com documentos escritos anteriores, mas também com "normas internas de aceitabilidade", particularmente no caso de um disfuncionamento nãoregulado (sabendo que as informações relativas a estas regulações podem ser transmitidas oralmente). Esta tarefa implica uma actividade de decisão. Esta primeira etapa conduz à elaboração de uma representação conceptual multi-dimensional dos elementos escolhidos, correspondendo a um potencial alvo.

73 A segunda etapa é uma fase de planificação e organização das informações em Dados e/ ou Acções e/ou Resultados, numa tentativa de definir uma estrutura textual compatível com o formalismo.

74 A etapa final corresponde à transformação da informação em palavras (vocabulário, formulação, incluído formas implícitas ou codificadas). Tal como foi demonstrado (em outras áreas da escrita) pelos resultados de trabalhos em psicologia experimental na área sobre a produção escrita (Bock \& Cutting, 1992 ; Bonnin \& Fayol, 1996 ; Fayol, 
1997 ; Alamargot, 2003), o "gargalo de estrangulamento" da transmissão que constitui a transformação das representações provenientes da actividade em DAR (segunda etapa), poderia ser difícil e custoso para o operador. As enfermeiras poderiam achar necessário procurar clarificações suplementares, necessitando de um novo contacto com a representação resultante da actividade, isto é, com os conhecimentos prévios relativos ao paciente e às acções realizadas. Tais retroacções (ciclos) são representadas na figura 4 pelas setas duplas verticais do modelo. O eventual custo pode colocar o problema da utilização real, a longo prazo e no decorrer da actividade, do formalismo prescrito. Ao longo do tempo, o risco de abandono espontâneo ou, pelo menos, de transformação deste sistema de notação das informações, pode ser antecipado. Qual o ganho para o operador da utilização deste formalismo, em termos de produção escrita e do seu uso ?

Os constrangimentos impostos pelo processo escrito não devem tornar-se a tarefa prioritária para o operador, quando comparada com a tarefa de transmissão de informações relevantes relativas ao acompanhamento da evolução do estado do paciente, que se tornam secundárias. Por exemplo, um item importante de informação (um sintoma de aviso) ser excluído porque não há lugar para ele na estrutura.

Figura 4 - Um modelo da produção escrita das transmissões em Dados, Acções e Resultados

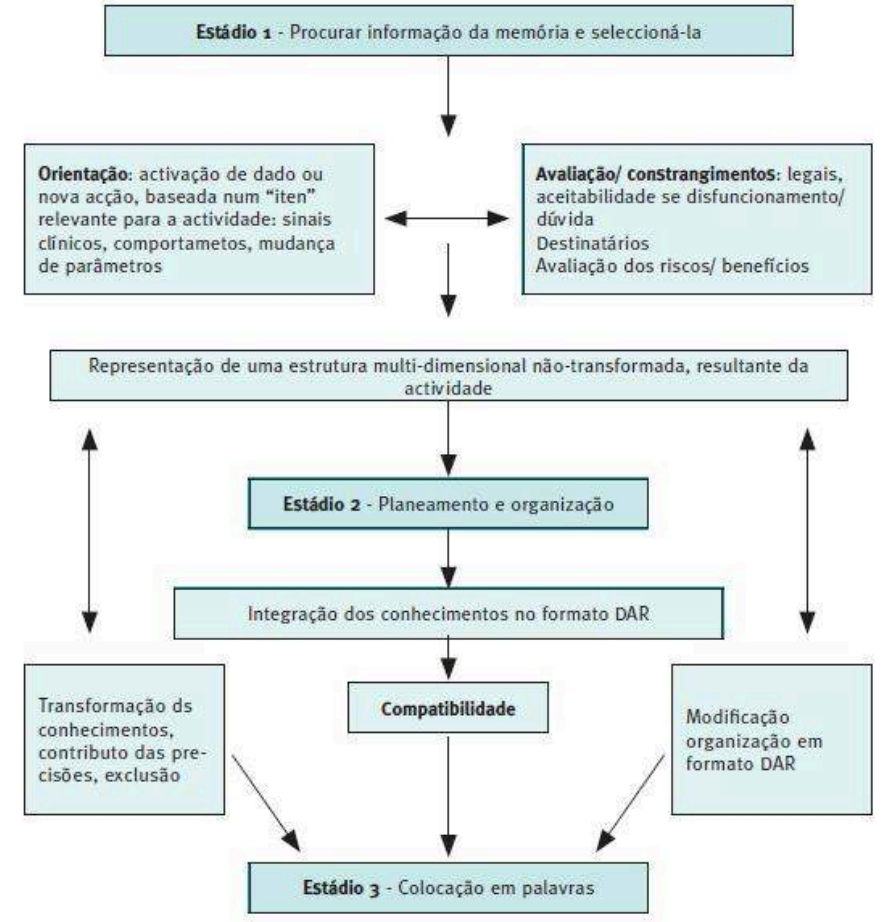

O nosso objectivo era avaliar a ergonomia do novo formato escrito, o documento de transmissão orientada formalizada em DAR, para o seu uso pelas enfermeiras na transmissão escrita da passagem de turno. Esta nova ferramenta foi sugerida, depois implementada, pela instituição hospitalar, no contexto do processo de acreditação do estabelecimento. Os benefícios esperados, a priori, com esta nova instrução, eram os de permitir um melhor acompanhamento do estado do paciente através da selecção de aspectos significativos da evolução do paciente, fornecer um rastreamento das transformações do paciente, capitalizar as informações escritas, fiáveis e práticas, para 
assegurar os cuidados continuados. No entanto, a instituição não planeou ou desenvolveu nenhuma análise prévia da actividade de transmissão oral e escrita, ou das competências das enfermeiras neste domínio, antes da introdução desta ferramenta. Tal análise teria permitido uma melhor compreensão do funcionamento das transmissões antes da introdução de uma ferramenta para a "melhoria" dos documentos escritos. Deparados com as dificuldades objectivas relacionadas com a implementação das transmissões orientadas, pretendia-se realizar uma formação profissional e era este o propósito do pedido que nos foi feito. No entanto, a nossa análise revelou que esta resposta pedagógica não era a questão a ser gerida. $\mathrm{Na}$ verdade, mostrámos que a ferramenta recomendada não estava adaptada às necessidades das profissionais. Longe de ser uma "ferramenta cognitiva" de ajuda para a tarefa de escrever documentos de transmissão escrita (Rogalski, 2001), parece que, no seu presente estado, o formato alvo+DAR é restritivo, não muito usado, não se adaptando às necessidades das enfermeiras e difícil de usar. Os processos de filtragem das informações entre missão escrita, que analisámos aqui, mostraram que as transmissões orais e escritas não contêm os mesmos traços e não têm o mesmo papel no acompanhamento do paciente. As questões da transmissão oral não parecem apenas comunicar nova informação relativa aos pacientes, mas antes de trocar informações a propósito de disfuncionamentos em curso de regulação ou não regulados, e portanto, previnem riscos para o paciente. Trocas de informação relativas a esses disfuncionamentos podem constituir ferramentas reais para o acompanhamento continuado dos pacientes. Contudo, com a introdução de novas normas para os registos escritos, as referências a estes cuidados desaparecem totalmente dos traços escritos. Mesmo que estes documentos de transmissão escrita preservem traços da actividade de supervisão das enfermeiras através de descrições de sinais clínicos ou de novos comportamentos do paciente, eles estão limitados à descrição dos disfuncionamentos regulados. Poderemos perguntar : até que ponto a introdução do novo formato para os documentos escritos não degradou as práticas existentes de transmissão escrita?

Se uma optimização da organização e a precisão das transmissões escritas parece necessária, e acima de tudo desejada pelos profissionais da instituição, poderia parecer que a estrutura de um tal documento escrito deveria aproximar-se à estrutura da actividade de supervisão das enfermeiras e da organização das representações operatórias resultantes desta actividade. Para além disso, a escolha da estrutura escrita, como em relação aos critérios de gestão de conteúdos (pertinência) e precisão da informação, poderia ser sujeita a um trabalho de co-concepção pelas profissionais e pelos prescritores da instituição hospitalar, no contexto do desenvolvimento de competências no domínio da passagem de turno. Parece especialmente necessário conhecer com precisão as necessidades reais das enfermeiras, para optimizar os documentos escritos. Isto seria particularmente útil para as utilizadoras principiantes, tal como demonstrado pela nossa comparação sistemática entre os três níveis de experiência.

Desta perspectiva, uma análise aprofundada dos documentos escritos "espontâneos" das enfermeiras, necessita ser realizada com o objectivo de melhor entender o seu funcionamento, e isto fora de qualquer modificação de formato. Os resultados apresentados anteriormente também indicam que parece necessário realizar um trabalho de definição da natureza e da forma dos documentos escritos esperados. Este trabalho poderia ser útil se direccionado para formatos mais próximos das representações "operatórias dinâmicas" do estado do paciente, construídas durante a 
actividade das enfermeiras. $\mathrm{Na}$ verdade, estas representações parecem ser "multidimensionais" : por exemplo, ao mesmo tempo que os sinais clínicos "objectivos" ou mensuráveis, elas incorporam também o vivido do paciente. Finalmente, uma reflexão sobre o conteúdo das informações relativamente à sua fiabilidade poderia ser útil. De facto, as mudanças de turno e as transmissões (escritas ou orais) constituem ou não uma parte extremamente crítica da tarefa prescrita ao operador que entra, pelo operador que parte, sendo uma actividade crucial à continuidade dos tratamentos?

\section{BIBLIOGRAFIA}

Alamargot, D., \& Dansac, C. (2003). Composer une consigne à partir de sources : ce que nous indiquent les activités graphiques et oculaires des rédacteurs. Journées d'études, Production, compréhension et usages des écrits techniques au travail. MSHS, Toulouse, 19-20 juin.

Bisseret, A., Sébillotte, S., \& Falzon, P. (1999). Manuel pratique pour l'analyse des activités expertes. Toulouse : Octarès.

Bock, J.K.,\& Cutting, J.C. (1992). Regulatingmentalenergy : performanceunits in language production. Journal of memory and language, 31, 99-127.

Bonnin, P., \& Fayol, M. (1996). L'étude en temps réel de la production du

langage écrit : Pourquoi et comment. Etudes de Linguistique Appliquée, nº 101, 8-19.

Boucheix, J.M. (2003). Ergonomie et formation : approche d'ergonomie cognitive de l'apprentissage professionnel. Psychologie Française, 48-2, 43-56.

Boucheix, J.M. (2005). L'accueil, orientation courtoise ou activité de résolution de problèmes, In M. Cerf, \& P. Falzon, Relations de service : Travailler avec le client (pp. 87-111). Paris : PUF.

Bourdin, B. (1994). Coût cognitif de la production verbale. Etude comparative oral/écrit chez l'enfant et l'adulte. Thèse pour le doctorat en psychologie de l'Université de Bourgogne.

Boutet, C. (1995). Les écrits professionnels. Sociologie du Travail, 4, 25-52.

Cellier, J.M., De Keyser, V., \& Valot, C. (1996). Le temps dans la conduite des systèmes dynamiques. Paris : PUF.

Cosnier, J., Grosjean, M., \& Lacoste, M. (1993). Soins et communications. Lyon : PUL.

Cerf, M., \& Falzon, P. (2005). Ergonomie de la relation de service : travailler avec le client. Paris PUF.

Cerf, M., Valléry, G, \& Boucheix, J.M. (2004). Les situations de service : enjeux et développement. In P. Falzon (Ed.), Traité d'Ergonomie (chapitre 34, pp. 565-581). Paris : PUF.

Davillerd, C., \& Grusenmeyer, C. (1994). La relève de poste : une période spécifique de travail collectif. Actes du XXVIIéme Congrès de la société d'ergonomie de langue Française (pp. 143-151). Toulouse : Octarès.

Errard, G., Kostulski, K., \& Trognon, A. (1996). Le dossier de soins : instrument de communication. A. A. R. C. H. 
Falzon, P. (1989). Ergonomie cognitive du dialogue. Grenoble : PUG. Falzon, P. (2004). Traité d'Ergonomie. Paris : PUF

Fayol, M. (1997). Des idées au texte : psychologie cognitive de la production écrite. Paris : P.U.F.

Giboin, A. (2004). La construction des référentiels communs dans le travail coopératif. In J.M.

Hoc, \& F. Darses (Eds.). Psychologie ergonomique : tendances actuelles (pp. 119-139). Paris : PUF

Grosjean, M., \& Lacoste, M. (1999). Communication et Intelligence Collective : Le Travail à

l'Hôpital. Paris : PUF.

Grusenmeyer C. (1995). Interaction langagière et représentation mentale partagée. Une étude de la relève de poste. Psychologie Française, 40, 47-59.

Grusenmeyer C. (1996). De l'analyse des communications à celle des représentations fonctionnelles partagées. Thèse de Doctorat de Psychologie Cognitive, INRS, A.8/1. 008.

Grusenmeyer, C., \& Trognon, A. (1996). Strutures of natural reasoning within functional dialogues. Pragmatics \& Cognition, 4 (2), 305-346.

Hayes, J.R., \& Nash, J.G. (1996). On the nature of planning in Writing. In

C.M. Levy, \& S. Randsell (Eds.), The science of writing (pp. 29-55). Mahwah, N.J. : Lawrence Erlbaum Associates.

Heurley, L. (1994). Traitement des textes procéduraux. Etude de psycholinguistique cognitive des processus de production et de compréhension chez des adultes non experts. Thèse pour le doctorat de Psychologie, Université de Bourgogne.

Hoc, J.M. (1996). Supervision et contrôle de processus. La cognition en situation dynamique. Grenoble : PUG.

Montmollin de, M., (1986). L'intelligence de la tâche. Bern : Peter Lang. Leplat, J. (1997). Regards sur l'activité en situation de travail. Paris : PUF, Le Travail Humain.

Levelt, W.J.M. (1989). Speaking : From intention to articulation. Cambridge : MA, MIT Press.

Levelt, W.J.M., \& Maassen, B. (1991). Lexical search and order of mention in sentence production. In W. Klein, \& W.J. levelt (Eds.), Crossing boundaries of linguistics (pp. 109-123). Dordrecht : Reichel.

Pastré, P. (1997). Didactique professionnelle et développement. Psychologie Française, 42, 89-10.

Rabardel, P. (1995). Les hommes et les Technologies. Approche Cognitive des Instruments Contemporains. Paris : Armand Colin.

Raufaste, E. (2001). Les mécanismes cognitifs du diagnostic médical. Optimisation et expertise. Paris : PUF.

Rogalski, J. (2001). Connaissances opérationnelles, compétences. In J. Leplat, \& M. de Montmollin (Eds.), Les compétences en ergonomie (pp. 250-275). Toulouse : Octarès Editions.

Rogalski, J. \& Samurçay, R. (1994). Modélisation d'un savoir de référence et transposition didactique dans la formation des professionnels de haut niveau. In G. Arsac, Y. Chevallard, J.L. Martinand, \& A. Tiberghien (Eds.). La transposition didactique à l'épreuve (pp. 35-71). Grenoble : La Pensée Sauvage Editions.

Vallery, G., Boucheix, J.M., Leduc, S. \& Cerf, M. (2004). Analyser les situations de service : questions de méthodes. In M. Cerf, \& P Falzon (Eds.). Situations de service : travailler dans l'interaction.(pp. 21-40). Paris : PUF. 


\section{RESUMOS}

O objectivo do trabalho apresentado neste artigo é avaliar a adaptação ergonómica de um novo formato de redacção das transmissões escritas, prescrito pelo hospital (CHU), às necessidades das enfermeiras durante a passagem de turno. 0 estudo centrasse particularmente na natureza da filtragem da informação que ocorre nestas transmissões. Foi utilizada uma démarche com 3 momentos, com uma população de 9 enfermeiras, responsáveis por 70 pacientes : (1) análise da actividade do trabalho de enfermagem antes da passagem, (2) análise da transmissão oral das enfermeiras que estão a sair de turno para as que estão a entrar no turno, (3) análise da consecutiva transmissão escrita das enfermeiras que estão a sair de turno. Os resultados mostram que o novo formato de escrita não está adaptado às necessidades das profissionais. Particularmente, os indicadores cruciais, os sinais clínicos e comportamentos, utilizados pelas enfermeiras durante a transmissão oral para a supervisão da evolução do estado dos pacientes, tendem a desaparecer da transmissão escrita. As regulações dos disfuncionamentos do estado do paciente, que são uma das questões centrais nas trocas orais de informação, estão ausentes das transmissões escritas. O diálogo na oralidade e os traços deixados por escrito desempenham papéis diferenciados no acompanhamento do paciente. Por fim, discutimos o modelo proposto de produção escrita, bem como recomendações com vista à concepção de "ferramentas" para a optimização das actividades de passagem de turno no hospital.

La movilidad es frecuentemente planteada como vector del desarrollo económico y como dimensión estructurante de inserción social. Menos visibilidad ha sido, aparentemente, atribuida a la discusión de los proyectos de movilidad por transporte público; de los criterios en que se fundamentan; y de lo que preconizan en términos de desarrollo local. La interrogación de esta articulación constituye nuestro hilo conductor, considerando igualmente la intencionalidad de los que participan en la concepción de las redes de transporte ; la perspectiva de los que prestan el servicio; y las especificidades territoriales.

En la estera de dos ejemplos concretos, reportados a dos realidades distintas - en Portugal, en un contexto rural, y en Mozambique, en un contexto urbano - es posible observar como la concentración de actividades, sobretodos económicos, constituye un factor determinante de las dinámicas de movilidad construidas. La reflexión toma lugar en las asimetrías territoriales potenciadas por los proyectos de desarrollo centralizados y en la necesidad de otro planteamiento de la movilidad, para la cual este artículo esboza algunas aportaciones.

L'objectif du travail présenté dans cet article est d'évaluer l'adaptation ergonomique d'un nouveau format de rédaction des transmissions écrites, prescrit par l'hôpital (CHU), aux besoins des infirmières lors de la relève de poste. L'étude se centre en particulier sur la nature du filtrage de l'information opérée dans les transmissions. Une démarche en trois temps a été suivie auprès d'une population de 9 infirmières en charge de 70 patients. : (1) analyse l'activité des soins auprès des patients, préalable à la relève, (2) analyse la relève orale des infirmières descendantes et montantes, (3) analyse de la relève écrite consécutive des infirmières descendantes. Les résultats montrent que le nouveau format d'écriture n'est pas adapté aux besoins des professionnelles. En particulier, les indicateurs cruciaux, signes cliniques et comportements, utilisés par les infirmières au cours de la relève orale pour la supervision de l'évolution de l'état des patients tendent à disparaître de la transmission écrite. Les régulations des dysfonctionnements de l'état $\mathrm{du}$ patient qui sont un enjeu majeur des échanges de la relève orale sont absentes des transmissions écrites. Le dialogue de l'oral et les traces laissées par l'écrit possèdent des rôles différents dans le suivi du patient. On discute enfin d'un modèle proposé de production écrite puis de préconisations en vue de la conception “d'outils » pour l'optimisation des activités de relève à l'hôpital. 
This study assesses the ergonomic quality of a new writing format used for the written transmission of activity during a nurse's handover in a hospital. This format called "targeted or focussed transmission" comes from a new prescription of hospital management designed to improve the written handover process. Our research focused on the information filtering process for each patient concerned by a shift handover. A three step methodology was designed, with the participation of 9 nurses in charge of 70 patients : (1) nursing work analysis before the handover, (2) oral handover analysis, (3) written handover analysis. Results show that the new writing format does not match the nurses' needs to perform high quality handovers. The main clues, clinical signs and patient behaviour, used by nurses during an oral handover, to supervise the monitoring of the patient state disappear from the content of the written handover document. Regulation activities carried out to manage areas of dysfunction within the patient's state, which are a main topic in the oral handover, are not included in the written handover document. The different roles played by oral dialogue and written traces in the patient monitoring activity have been analysed and discussed. Finally, a cognitive model of professional written production is proposed and discussed and also some recommendations to design writing tools for the optimization of written handover documents.

\section{ÍNDICE}

Palabras claves: Movilidad, transportes viales, desarrollo, territorio, polos generadores de movilidad

Mots-clés: relève de poste, transmissions orales et écrite, format d'écriture, modèle de production

Keywords: working handover, written transmissions, written production model

Palavras-chave: passagem de turno, transmissões orais e escritas, formato de escrita, modelo de produção

\section{AUTORES}

\section{JEAN-MICHEL BOUCHEIX}

Université de Bourgogne, LEAD/CNRS, UMR 5022, Pôle AAFE, Esplanade Erasme, 21065 Dijon, BP : 26513

Jean-Michel.Boucheix@u-bourgogne.fr

\section{MICHÈLE COIRON}

C.H.U, Enfermeira Supervisora, Responsável da Formação Université de Bourgogne, LEAD/CNRS, UMR 5022, Pôle AAFE, Esplanade Erasme, 21065 Dijon, BP : 26513 